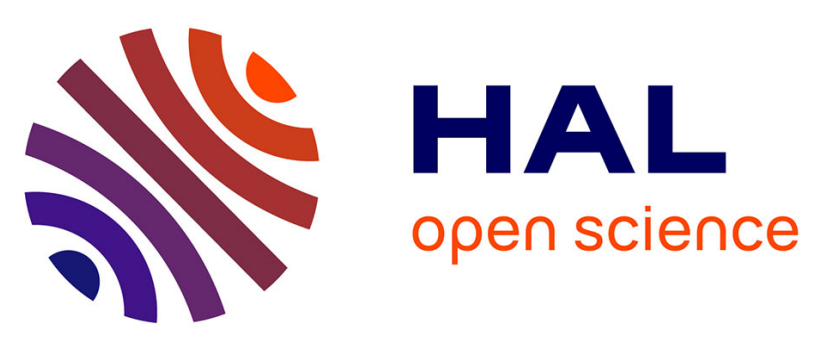

\title{
Additive Protective Effects of Sacubitril/Valsartan and Bosentan on Vascular Remodeling in Experimental Pulmonary Hypertension
}

Marie-Camille Chaumais, Mohamed Reda Amar Djessas, Raphaël Thuillet, Amélie Cumont, Ly Tu, Guillaume Hébert, Pauline Gaignard, Alice Huertas, Laurent Savale, Marc Humbert, et al.

\section{To cite this version:}

Marie-Camille Chaumais, Mohamed Reda Amar Djessas, Raphaël Thuillet, Amélie Cumont, Ly $\mathrm{Tu}$, et al.. Additive Protective Effects of Sacubitril/Valsartan and Bosentan on Vascular Remodeling in Experimental Pulmonary Hypertension. Cardiovascular Research, 2020, pp.cvaa200. $10.1093 /$ cvr/cvaa200 . inserm-02907132

\section{HAL Id: inserm-02907132 https://www.hal.inserm.fr/inserm-02907132}

Submitted on 27 Jul 2020

HAL is a multi-disciplinary open access archive for the deposit and dissemination of scientific research documents, whether they are published or not. The documents may come from teaching and research institutions in France or abroad, or from public or private research centers.
L'archive ouverte pluridisciplinaire HAL, est destinée au dépôt et à la diffusion de documents scientifiques de niveau recherche, publiés ou non, émanant des établissements d'enseignement et de recherche français ou étrangers, des laboratoires publics ou privés. 


\title{
Additive Protective Effects of Sacubitril/Valsartan and Bosentan on Vascular Remodeling in Experimental Pulmonary Hypertension
}

\author{
Short Title: Dual therapy with LCZ 696 plus bosentan in PH
}

Marie-Camille Chaumais ${ }^{1,2,3}$, Mohamed Reda Amar Djessas ${ }^{1,2}$, Raphaël Thuillet ${ }^{1,2}$, Amélie MarieCamille Chaumais ${ }^{1,2,3}$, Mohamed Reda Amar Djessas ${ }^{1,4}$, Raphaël Thuillet ${ }^{1,4}$, Amélie Cumont ${ }^{1,4}$, Ly $\mathrm{Tu}^{1,4}$, Guillaume Hebert ${ }^{5}$, Pauline Gaignard ${ }^{6,7}$, Alice Huertas ${ }^{1,4,7}$, Laurent Savale ${ }^{1,4,7}$, Marc Humbert ${ }^{1,4,7}$, Christophe Guignabert ${ }^{1,4}$

\begin{abstract}
${ }^{1}$ INSERM UMR_S 999 «Pulmonary Hypertension: Pathophysiology and Novel Therapies», Hôpital Marie Lannelongue, $92 \overline{3} 50$ Le Plessis-Robinson, France; ${ }^{2}$ Université Paris-Saclay, Faculté de Pharmacie, 92290 Châtenay-Malabry, France; ${ }^{3}$ Assistance Publique - Hôpitaux de Paris (AP-HP), Service de Pharmacie, Hôpital Bicêtre, 94270 Le Kremlin-Bicêtre, France ; ${ }^{4}$ Université Paris-Saclay, Faculté de Médecine, 94270 Le Kremlin-Bicêtre, France; ${ }^{5}$ Hôpital Marie Lannelongue, Service pharmacie, 92350 Le Plessis-Robinson,

France ; ${ }^{6}$ AP-HP, Laboratoire de biochimie, Hôpital Bicêtre, 94270 Le Kremlin-Bicêtre, France, ${ }^{7}$ AP-HP, Service de Pneumologie et Soins Intensifs Respiratoires, Hôpital Bicêtre, 94270 Le Kremlin-Bicêtre, France;
\end{abstract}

Address correspondence to: Christophe Guignabert, PhD; INSERM UMR_S 999; 133, Avenue de la Résistance; 92350 Le Plessis-Robinson, France. Tel: +33-1-40948833; Fax: +33-1-40942522; E-mail: christophe.quignabert@inserm.fr

Manuscript word count: 4612

\section{Scientific knowledge on the subject}

- Although pulmonary arterial hypertension (PAH) is characterized by obliterative vascular remodeling in the lungs, severity of symptoms and survival are strongly associated with right ventricular function, and right heart failure is the main cause of death in patients with $\mathrm{PAH}$.

- Sacubitril/valsartan (LCZ 696) has been shown to improve mortality and reduce hospitalizations in patients with heart failure (HF) with reduced ejection fraction (HFrEF).

- LCZ 696 alone reduces pulmonary pressures, vascular remodeling and right ventricular hypertrophy in the Sugen/Hypoxia (SuHx) rat model.

\section{What this study adds to the field?}

- LCZ 696 alone had also beneficial effects in the monocrotaline (MCT) rat model of severe pulmonary hypertension $(\mathrm{PH})$.

- Combination therapy of LCZ 696 and bosentan had additive vascular protective effects against the pulmonary vascular remodeling and $\mathrm{PH}$ in the MCT and sugen/hypoxia (suHx) rat models of severe $\mathrm{PH}$.

- LCZ 696 has anti-proliferative effect on cultured human pulmonary artery smooth muscle cells (PA-SMCs) derived from patients with idiopathic $\mathrm{PAH}$, an effect that is more pronounced in presence of bosentan

- The beneficial effect of LCZ $696(30 \mathrm{mg} / \mathrm{kg} / \mathrm{day})$ and bosentan $(100 \mathrm{mg} / \mathrm{kg} / \mathrm{day})$ in the MCT and SuHx rat models is associated with an increased in the plasma levels of cyclic GMP (cGMP) and atrial natriuretic peptide (ANP) 


\section{Abstract}

2 Aims: Although right ventricular (RV) function is an important determinant of morbidity and mortality in

3 patients with pulmonary arterial hypertension (PAH), there is no treatment targeting directly the RV. We evaluate the efficacy of sacubitril/valsartan (LCZ 696) as add-on therapy to bosentan in rats with severe pulmonary hypertension $(\mathrm{PH})$.

Methods and Results: Combination therapy of LCZ 696 and bosentan has additive vascular protective effects against the pulmonary vascular remodeling and $\mathrm{PH}$ in two preclinical models of severe $\mathrm{PH}$. Compared with monotherapy, co-treatment of LCZ 696 (30 or $68 \mathrm{mg} / \mathrm{kg} /$ day for 2 weeks, per os) and bosentan $(100 \mathrm{mg} / \mathrm{kg} /$ day for 2 weeks, per os) started 7-day after monocrotaline (MCT) injection substantially reduces pulmonary pressures, vascular remodeling and RV hypertrophy and fibrosis in rats. Consistent with these observations, cotreatment of rats with established $\mathrm{PH}$ induced by sugen/hypoxia (SuHx) with LCZ 696 (30 mg/kg/day for 3 weeks, per os) and bosentan (100mg/kg/day for 3 weeks, per os) started 5 weeks after Sugen injection partially attenuate total pulmonary vascular resistance and cardiovascular structures. We also obtained evidence showing that LCZ 696 has antiproliferative effect on cultured human pulmonary artery smooth muscle cells (PA-SMCs) derived from patients with idiopathic $\mathrm{PAH}$, an effect that is more pronounced in presence of bosentan. Finally, we found that the plasma levels of ANP and cGMP are higher in rats co-treated with LCZ 696 (30 mg/kg/day) and bosentan $(100 \mathrm{mg} / \mathrm{kg} / \mathrm{day})$ than in MCT and SuHx rats treated with vehicle.

Conclusion: Dual therapy with LCZ 696 plus bosentan proved significantly superior beneficial effect to LCZ 696 or bosentan alone on vascular remodeling and severity of experimental PH.

Keywords: Pulmonary arterial hypertension $\bullet$ Pulmonary vascular remodeling $•$ Cardiac dysfunction • Entresto 


\section{Introduction:}

\section{$47 \quad$ Methods}

The authors declare that all supporting data are available within the article and its Online Data

Pulmonary arterial hypertension (PAH) is a rare and devastating disease in which the progressive increase in mean pulmonary artery pressure (mPAP) is due to an intense pulmonary vascular remodelling, leading to right ventricular overload, hypertrophy, and ultimately right heart failure and death ${ }^{1}$. Right heart function is the main determinant of prognosis in $\mathrm{PAH}$; however, there is currently no treatment available that directly target the right ventricle (RV).

LCZ 696 (sacubitril/valsartan) is a combination drug with a proven efficacy in chronic HF wirh reduced ejection fraction in reducing mortality and hospitalization ${ }^{2}$. In this novel approach for the treatment of heart failure, sacubitril is a pro-drug that upon activation acts as a potent inhibitor of neprilysin, an endopeptidase that breaks down several vasoactive peptides including natriuretic peptides, bradykinin, endothelin and angiotensin (Ang)-II. Since inhibition of neprilysin increases of plasmatic levels of both, natriuretic peptides and Ang-II (with opposite biological effects), sacubitril is currently used in combination with valsartan, an AT1 receptor blocker. Therefore, LCZ 696 by enhancing natriuretic peptides ${ }^{3}$ and suppressing the renin-angiotensin-aldosterone system (RAAS) ${ }^{4}$ is a desirable therapeutic goal to supplement the current PAH treatment options. Consistent with this notion, a beneficial effect of LCZ 696 alone has been recently reported in the Sugen/Hypoxia (SuHx) rat model of severe pulmonary hypertension $(\mathrm{PH})^{5,6}$, but its efficacy as add-on therapy to a specific therapy used in clinical practice for PAH management has not been studied yet.

The purpose of this study was to determine the potential benefit of combination therapy of LCZ 696 and bosentan, a specific PAH treatment, in two complementary preclinical models [the monocrotaline (MCT) and Sugen/Hypoxia (SuHx) rat models] of severe $\mathrm{PH}$.

$$
\text { Supplement. All animal procedures were designed to conform to the guidelines from Directive }
$$
2010/63/EU of the European Parliament on the protection of animals used for scientific purposes and the protocols used were approved by the local Ethics Committee of the University Paris-Saclay 
(CEEA26), Le Plessis-Robinson, France. All experimental studies using human samples comply with the Declaration of Helsinki and were approved by the local ethics committee (Comité de Protection des Personnes lle-de-France VII). All patients gave informed consent before the study.

\section{Animals and in vivo treatment}

Young male Wistar rats (100 g, Janvier Labs, Saint Berthevin, France) were studied 3 weeks after a single subcutaneous injection of MCT (60 mg/kg; Sigma-Aldrich) or vehicle (Figure 1A). Male rats were used to minimize hormonal effects (e.g., of estrogen). At day-7, MCT-injected rats were randomly divided into five groups and treated for 2 weeks with daily per os treatment with vehicle [drinking water], or via oral gavage with LCZ $696(68 \mathrm{mg} / \mathrm{kg} / \text { day })^{5}$, or bosentan $(100 \mathrm{mg} / \mathrm{kg} /$ day $)$ alone ${ }^{7}$, or with the combination of bosentan (100 mg/kg/day) and LCZ 696 (30 mg/kg/day or $68 \mathrm{mg} / \mathrm{kg} /$ day). Two additional groups of healthy rats were randomly divided into two groups and treated for 2 weeks with daily per os treatment with vehicle [drinking water] or with the combination of LC Z696 (68mg/kg/day) and bosentan $(100 \mathrm{mg} / \mathrm{kg} /$ day) [oral gavage].

To validate our findings obtained in the MCT rat model, a second rat model of severe PH was used (Figure 1B). Briefly, young male Wistar rats received a single subcutaneous injection of SU5416 $(20 \mathrm{mg} / \mathrm{kg})$ and were exposed to normobaric hypoxia for 3 weeks before to return to room air for 5 weeks. At 5-weeks post-SU5416 injection (D0), pulsed-wave doppler during transthoracic echocardiography was used to validate the presence of established $\mathrm{PH}$ by assessing pulmonary artery acceleration time (AT) to right ventricular ejection time (ET) ratio, using Vivid E9 (GE Healthcare, Velizy-Villacoublay, France). Then, SuHx rats were randomized to receive vehicle (drinking water), or the combination of LCZ 696 (30 mg/kg/day) and bosentan (100mg/kg/day) [oral gavage].

At the end of these protocols (D21), animals were anesthetized with isoflurane (2.0\% in oxygen) and transthoracic echocardiography was used to blindly determine the $A T / E T$ and $R V /(R V+L V)$ distance ratio and evaluate right ventricular function by assessment of the tricuspid annular plane systolic excursion (TAPSE). In addition, pulmonary pressures were measured blindly by closed chest right heart catheterization, as previously described ${ }^{8-13}$. Briefly, a polyvinyl catheter was introduced into the right jugular vein and pushed through the RV into the pulmonary artery. In parallel, a carotid artery was cannulated for the measurement of systemic arterial pressure. Cardiac output (CO) in rats was measured using the thermodilution method. Hemodynamic values were automatically calculated by the 
physiological data acquisition system (LabChart 7 Software; ADInstruments Co., Shanghai, China). After measurement of hemodynamic parameters, the thorax was opened and the left lung immediately removed and frozen. The right lung was fixed in the distended state with formalin buffer. The right ventricular hypertrophy was assessed by the Fulton index [weight ratio of RV and (LV + septum)] and the percentage of wall thickness $[(2 \times$ medial wall thickness/ external diameter $) \times 100]$ and of muscularized vessels were performed as previously described ${ }^{8-13}$.

\section{ELISA and Immunostaining}

Concentrations of cyclic guanosine monophosphate (cGMP) and atrial natriuretic peptide (ANP) in plasma were evaluated using a rat cGMP ELISA Kits (KGE003, Bio-techne SAS, Noyal Châtillon sur Seiche, France) and ANP ELISA Kits (ab108797, Abcam, Paris, France) according to the manufacturer instructions. Immunohistochemistry staining for alpha-SMA (Sc32251), proliferating cell nuclear antigen (PCNA, sc-56), and CD68 (sc-20060, Santa Cruz Biotechnology, Heidelberg, Germany) were performed in rat lung paraffin sections $5,8,10,14,15$. Briefly, lung sections were deparaffined and stained with hematoxylin and eosin (H\&E) (Sigma-Aldrich, Saint-Quentin Fallavier, France), picrosirius red, or incubated with retrieval buffer. Then, sections were saturated with blocking buffer and incubated overnight with specific antibodies, a vectastain $A B C$ kit according to the manufacturer's instructions (Abcys, Courtaboeuf, France) and counterstained with Hematoxylin (Sigma-Aldrich). Images were taken using Eclipse 80i microscope (Nikon Instruments, Champigny-sur-Marne, France).

\section{Isolation, Culture, and Functional Analysis Human PA-SMCs}

Primary human pulmonary artery smooth muscle cells (PA-SMCs) were isolated using an explantoutgrowth method and cultured as previously described ${ }^{9,11,12,16}$. Briefly, small pieces of freshly isolated pulmonary arteries were cultured in Dulbecco modified Eagle medium supplemented with $15 \%$ fetal calf serum (FCS), 2 mM L-glutamine, and antibiotics. The isolated pulmonary PA-SMCs were strongly positive for $\alpha$-smooth muscle actin, smooth muscle-specific SM22 protein, and calponin, and negative for von Willebrand factor and CD31. Cells were routinely tested for mycoplasma and used at early passages $\leq 7$. As previously described, PA-SMCs were seeded in 96-well plates at a density of 3000 cells/well and allowed to adhere. After being subjected to growth arrest for 48 hours in medium lacking FCS, the PA-SMCs were treated with vehicle or bosentan $(50 \mu \mathrm{M} \text {, Selleckchem, Houston, TX, USA })^{17}$, 


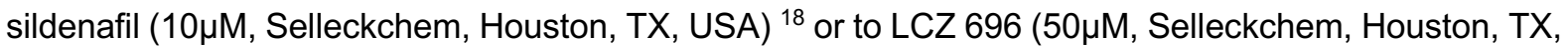
USA) in presence of $5 \%$ FCS. Then, PA-SMC proliferation was assessed by measuring 5-bromo-2deoxyuridine incorporation using a DELFIA kit (Perkin Elmer) as recommended by the manufacturer. BrdU incorporation was determined by measuring Eu-fluorescence in a time-resolved EnVision Multilabel Reader (PerkinElmer, Waltham, MA, USA).

\section{Statistical analyses}

The data are expressed as mean \pm SD. Statistical significance was tested using one-way analysis of variance (ANOVA) with post hoc testing for multiple comparisons by Bonferroni's test. To analyse and compare the disease severity among the different groups, the mean of each groups was compared with the mean of the control vehicle-treated rats. To analyse and compare the efficacy of the different treatments on the physiological parameters and vascular remodeling induced by MCT, the mean of each groups was compared with the mean of the MCT-injected rats. To analyse and compare the efficacy of LCZ 696 alone or with bosentan at the two different doses on the physiological parameters and vascular remodeling induced by MCT, the mean of these 4 groups of treated MCT rats was analysed with post hoc testing for multiple comparisons by Bonferroni's test for multiple comparisons. Significant difference was assumed at a $p$ value of $<0.05$.

\section{Results}

\section{Additive Beneficial Effects of LCZ 696 with Bosentan on the Progression of PH in the MCT Rat Model}

First, we examined the effect of chronic treatment of LCZ 696 with bosentan against the progression of $\mathrm{PH}$ induced in rats by a single subcutaneous injection of MCT. In the vehicle-treated MCT group, two rats died within 21 days after monocrotaline treatment. By contrast, all rats in the other groups survived the experiment. Therefore, the 21-day survival rates in the vehicle, bosentan, LCZ $696(30 \mathrm{mg} / \mathrm{kg})$, LCZ $696(68 \mathrm{mg} / \mathrm{kg})$, and LCZ $696(68 \mathrm{mg} / \mathrm{kg})$ with bosentan $(100 \mathrm{mg} / \mathrm{kg})$ groups were $84.6 \%, 100 \%, 100 \%$, $100 \%$, and $100 \%$, respectively.

At day-21, a decrease in right ventricular function (assessed by TAPSE) and in the ratios of AT/ET were found in vehicle-treated MCT rats compared with control rats, together with an increase in $R V /(R V+L V)$ 
distance (Figure 2A). Invasive hemodynamic using right heart catheterization confirmed the presence of $\mathrm{PH}$ in vehicle-treated MCT rats as reflected by the increase in MPAP, total pulmonary vascular resistance (TPVR) and a decrease in CO (Figure 2B). Consistent with these results, vehicle-treated MCT rats exhibited also an increase in the percentages of medial wall thickness and of muscularized distal pulmonary arteries (Figure 3A) together with higher numbers of CD68 and PCNA positive cells (Figure 3B). Furthermore, right ventricular remodeling (Fulton index/body weight ratio) and increased accumulation of collagen (stained with picosirius red) in the RV were also found in vehicle-treated MCT (Figure 4). MCT rats treated with the combination of LCZ 696 and bosentan exhibit higher TAPSE, $A T / E T$, reduced $R V /(R V+L V)$ ratio and attenuated $m P A P, T P V R$ and decrease in CO compared to vehicle-treated MCT rats (Figure 2). Consistent with these results the percentages of medial wall thickness and of muscularized distal pulmonary arteries, numbers of CD68 and PCNA positive cells were substantially reduced (Figure $\mathbf{3 A - B}$ ) as well as the right ventricular hypertrophy (Figure 4). In addition, we also noted a reduced accumulation of collagen in the RV of MCT rats treated with the combination of LCZ 696 and bosentan compared to vehicle-treated MCT rats (Figure 4). Interestingly, the administration of bosentan or LCZ 696 alone in MCT-injected rats also significantly reduced TPVR compared to vehicle-treated MCT rats $(733 \pm 161$ and $427 \pm 113$ versus $1139 \pm 230 \mathrm{mmHg} / \mathrm{mL} / \mathrm{min}$, respectively; $p<0.001)$, but at a lower level than the combination therapy (305 \pm 155 and $285 \pm 73$ $\mathrm{mmHg} / \mathrm{mL} / \mathrm{min}$ at 30 and $68 \mathrm{mg} / \mathrm{kg} /$ day, respectively; $\mathrm{p}<0.001$ ) (Figure $2 \mathrm{~B}$ ). In contrast to the others groups of rats, MCT injected rats treated with bosentan and the highest dose of LCZ 696 tested (68mg/kg/day) exhibited an $\sim 20 \%$ reduction in mean systemic arterial blood pressure (mBP) (Figure 2B).

\section{Confirmation of the Efficacy of the Combination Therapy of LCZ 696 and Bosentan in the} Progression of PH in the Sugen/Hypoxia Model in Rats

Since animal models mimic only parts of the human condition ${ }^{19}$, we next tested the efficacy of dual therapy with LCZ 969 plus bosentan in a second experimental model of severe $\mathrm{PH}$, namely the SuHx rat model. We evaluated the effects of a 3-week combination therapy of bosentan $(100 \mathrm{mg} / \mathrm{kg} / \mathrm{day})$ and LCZ 696 (30 mg/kg/day) against the progression of PH induced by a single subcutaneous injection of Sugen (SU5416; $20 \mathrm{mg} / \mathrm{kg})$ followed by 3 weeks of hypoxia $\left(10 \% \mathrm{FiO}_{2}\right)$ and 5 weeks of normoxia (Figure 1B). Before treatment (D0), transthoracic echocardiography validated that SuHx rats exhibit 
established $\mathrm{PH}$, as reflected by lower values for TAPSE and AT/ET ratio and higher values of right ventricular chamber dimension $(\mathrm{RV} /(\mathrm{RV}+\mathrm{LV})$ ratio) (Figure 5A). Consistent with our observations obtained in the previous model, rats treated with the combination of LCZ 696 and bosentan are protected against the development of $\mathrm{PH}$-induced by Sugen/Hypoxia (Figure $\mathbf{5}$ and $\mathbf{6}$ ). No rats died during the studies. At 8-weeks post-SU5416 injection (D21), in SuHx rats treated with vehicle, a decrease in TAPSE and AT/ET ratio were found together with an increased in RV/(RV+LV) by transthoracic echocardiographic assessment compared with control rats (Figure 5A). Consistent with these echocardiographic data, mPAP, TPVR (Figure 5B), percentages of medial wall thickness and of muscularized distal pulmonary arteries (Figure 6A), and numbers of CD68 and PCNA positive cells (Figure 6B) were increased in vehicle-treated SuHx rats compared to control animals. In addition, values of Fulton index/body weight ratio and collagen accumulation in the RV were also increased in vehicle-treated SuHx rats (Figure 6C). As shown in the rat model of MCT-induced $\mathrm{PH}$, SuHx rats treated with bosentan (100mg/kg/day) and LCZ $696(30 \mathrm{mg} / \mathrm{kg} /$ day) are also protected against the accumulation of collagen in the RV compared to vehicle-treated SuHx rats $(5.0 \pm 2.4$ versus $8.6 \pm 0.3$, respectively; $\mathrm{p}<0.01$ ) (Figure 6C). Of note, no differences were found in values of mBP $(97 \pm 7$ versus $92 \pm 8$, respectively, NS) between SuHx rats treated with bosentan $(100 \mathrm{mg} / \mathrm{kg} /$ day) and LCZ 696 (30mg/kg/day) and vehicle-treated SuHx or control rats (Figure 5B).

\section{Treatments with LCZ $696(30 \mathrm{mg} / \mathrm{kg} / \mathrm{d})$ and Bosentan $(100 \mathrm{mg} / \mathrm{kg} / \mathrm{d})$ significantly increased} cGMP and ANP circulating levels in preclinical models of $P H$

cGMP is a central and critical second messenger that regulates contractility and accumulation of PASMCs by modulating the activity of cGMP-dependent kinases, phosphodiesterases and ion channels 20. Compared with MCT or SuHx rats treated with vehicle, MCT- or SuHx-rats treated with the combination of bosentan and LCZ 696 (30 mg/kg/d) exhibits increase in circulating cGMP levels (Figure 7A). Similarly, we found that MCT and SuHx rats treated with the combination of bosentan and LCZ 696 (30 mg/kg/d) exhibit higher levels of ANP in plasma as compared with MCT rats treated with vehicle or bosentan- and vehicle-treated SuHx-rats (Figure 7B).

4. LCZ 696 attenuates the pro-proliferative phenotype of cultured PA-SMCs derived from idiopathic PAH (IPAH) patients 

treatment on the proliferative potential of cultured PA-SMCs derived from idiopathic PAH patients. BrdU incorporation assay showed that LCZ 696 has anti-proliferative effect on cultured human PA-SMCs derived from patients with idiopathic $\mathrm{PAH}$, an effect that is more pronounced in presence of bosentan (Figure 7C) or of sildenafil (Supplemental Fig. 1).

\section{Discussion}

To our knowledge this is the first study assessing benefit of LCZ 696 as an add-on therapy to bosentan, a specific $\mathrm{PAH}$ treatment, in two experimental models of severe $\mathrm{PH}$. Our data indicate that combination therapy of LCZ 696 and bosentan attenuates right ventricular hypertrophy, pulmonary vascular remodeling and decreases inflammatory cell infiltration in lungs of MCT or SuHx rats. We found that the dual therapy had a more pronounced beneficial effect against the pulmonary vascular remodeling in MCT rats than LCZ 696 or bosentan treatment used alone. These in vivo observations were replicated in vitro, with a greater anti-proliferative effect for LCZ $696+$ bosentan on PA-SMCs derived from idiopathic PAH than LCZ 696 or bosentan used alone. We also report evidence that beneficial effect of LCZ $696(30 \mathrm{mg} / \mathrm{kg} / \mathrm{day})$ and bosentan $(100 \mathrm{mg} / \mathrm{kg} / \mathrm{day})$ in the MCT and SuHx rat models is associated with an increased in the plasma ANP and cGMP levels.

Previous animal studies have reported that LCZ 696 alone has beneficial effects in the SuHx rat model of severe $\mathrm{PH}^{5,6}$, but its efficacy in the MCT rat model and as an add-on therapy with other PAHtargeted molecules have not been studied before. LCZ 696 treatment was found to be ineffective in a rat model of pressure overload induced RV hypertrophy caused by pulmonary trunk banding (PTB) ${ }^{5}$, suggesting a direct positive effect of LCZ 696 treatment against the remodeling of the pulmonary vasculature. The lack of efficacy of valsartan alone in the SuHx rat model was also reported ${ }^{6}$, supporting the notion that suppressing RAAS in experimental $\mathrm{PH}$ is more effective with a pharmacological augmentation of natriuretic peptides. To test the efficacy of LCZ 696 as an add-on therapy to other PAH-targeted molecules, we have chosen to use the dual endothelin-receptor antagonist bosentan ${ }^{22}$ that is a well-known active substance with established efficacy and tolerability. Of note, bosentan as the other current PAH-targeted molecules do not act directly by prevention of right 
heart failure, but they mainly cause effective pulmonary vasodilation ${ }^{22-24}$. To induce experimental $\mathrm{PH}$ and further validate the interest of LCZ 696 in PAH, we have chosen to use a different but complementary animal model of severe $\mathrm{PH}$ induced by the administration of MCT that is a wellestablished to cause $\mathrm{PH}$ and right heart failure ${ }^{19}$. Our data indicate that co-administration of bosentan with LCZ 696 in MCT-injected rats is more efficient on TPVR, pulmonary vascular remodeling and cardiac fibrosis than bosentan or LCZ 696 used alone. As frequently observed in several patients treated with LCZ $696{ }^{25}$, the highest dose of LCZ 696 tested in our MCT-injected rats was associated with a significant reduction in $\mathrm{mBP}$. We found that LCZ 696 at a dose of $30 \mathrm{mg} / \mathrm{kg} / \mathrm{day}$ in association with bosentan (100mg/kg/day) did not impact the mBP neither in MCT-injected rats nor in SuHx rats, and thus represents the best efficacy-safety profile. Since no SuHx rats were treated with bosentan or LCZ 696 alone, we cannot exclude that these monotherapies would have shown a more pronounced positive effects in SuHx rats as compared to the dual therapy. Consistent with previous studies ${ }^{26,27}$, bosentan was only mildly effective as monotherapy at $100 \mathrm{mg} / \mathrm{kg} /$ day in MCT rats. Indeed, bosentan treatment decreased TPVR by improving cardiac output without changing mPAP. We also noted that co-administration of bosentan with LCZ 696 has better efficacy in MCT-injected rats than in SuHx rats. These differences could be partly explained by the fact that the SuHx rat model tends to progress more slowly than the MCT rat model, together with a more compromised RV function. Because the MCT rat model of $\mathrm{PH}$ is characterized by a high mortality in young rats that started at 21 days after injection and also for ethical concerns, treatments were daily administered at D7 for 2 weeks, excluding any effect of treated when severe $\mathrm{PH}$ was already present. However, these differences could also be due to differences in pathophysiology involved in these two animal models or in the age when the treatment period is starting ( 1 week-post MCT injection versus 5 weeks-post SU5416 injection). In contrast to our results obtained in adult rats with the combined use of a neprilysin inhibitor and an angiotensin receptor blocker, mice deficient in neprilysin from birth are more prone to remodel their pulmonary vessels in response to chronic hypoxia compared to their littermate controls ${ }^{28}$. While some of this difference could be explained by interspecies differences, or by the effects of knockout versus pharmacological inhibition, the pleiotropic functions of ANP and other natriuretic peptides in the heart and in the vascular system that are independent of blood pressure regulation could also explain this discrepancy ${ }^{29}$. 
260 Consistent with our findings showing that combination therapy of LCZ 696 and bosentan attenuates

261 right ventricular hypertrophy, pulmonary vascular remodeling and decreases inflammatory cell 262 infiltration in lungs of MCT or SuHx rats, higher levels of ANP and cGMP were found in plasma of rats 263 treated with the dual therapy. Elevation of circulating ANP in chronically hypoxic-rats treated with LCZ $2646966^{30-33}$ and in SuHx-rats treated with LCZ 696 was already reported ${ }^{6}$, but no data were available in 265 SuHx rats co-treated with bosentan or in MCT rats. Herein, our findings also indicated that combination therapy of LCZ 696 and bosentan increased circulating cGMP levels. cGMP is a central and critical second messenger generated in response to nitric oxide or natriuretic peptides ${ }^{34,35}$ and regulates contractility and accumulation of PA-SMCs by modulating the activity of cGMP dependent kinases, phosphodiesterase and ion channels ${ }^{20}$. Consistent with our findings, Clements and co-workers have also reported that LC Z696 alone increased cGMP levels in SuHx rats ${ }^{6}$, suggesting that treatment efficacy is at least partly related to cGMP and ANP signaling. The demonstration that LCZ 696 has antiproliferative effect that is more pronounced in presence of bosentan or sildenafil on human PA-SMCs derived from patients with idiopathic PAH strongly support that LCZ 696 could be considered as a potentially promising add-on therapy for $\mathrm{PAH}$. Consistent with this notion, it has been reported that patients taking the neprilysin inhibitor racecadotril exhibit a rapid increase in plasma cGMP levels within the 6 hours following oral administration, a phenomenon associated with a decrease in PVR ${ }^{36}$. Unfortunately, the long-term impact of racecadotril was not assessed in this recent clinical trial. However, LCZ 696 treatment was already reported to reduced pulmonary pressures in two cases of PH patients due to left heart disease ${ }^{37}$ and reverses $\mathrm{PH}$ in end-stage heart failure patients waiting transplantation ${ }^{38}$. Therefore, these results taken with our observations should encourage evaluation of LCZ 696 or oether angiotensin receptor-neprilysin inhibitors in human PAH.

In summary, our study provides the first evidence that LCZ 696 could be used as an add-on therapy to bosentan, to potentially prevent or even limit the remodeling of pulmonary blood vessels and to enhance cardiac function in $\mathrm{PH} / \mathrm{PAH}$ probably through elevation of ANP and cGMP. Although further experiments are required to identify the exact mechanism underlying the beneficial effects of neprilysin inhibition in these two preclinical models, we report evidence that dual therapy with LCZ 696 plus bosentan might represent a promising therapeutic strategy for $\mathrm{PAH}$ patients in addition to the current available therapy. 
The authors thank Mina Ottaviani for her help with the immunohistochemical identification and quantification of PCNA and CD68 positive cells in lung sections. The authors also thank Maria-Rosa Ghigna, Caroline Communaux and all technicians and pathologists from the Department of Pathology at Marie Lannelongue hospital for their expertise and support. This research was supported by grants from the French National Institute for Health and Medical Research (INSERM), the University ParisSaclay, the Marie Lannelongue Hospital, the French National Agency for Research (ANR) grant no. ANR-16-CE17-0014 (TAMIRAH) and ANR-18-RHUS-0006 (RHU DESTINATION 2024), the Fondation de la Recherche Médicale (FRM) grant no. DEQ20150331712 (Equipe FRM 2015), and in part by the Département Hospitalo-Universitaire (DHU) Thorax Innovation (TORINO), the Assistance PubliqueHôpitaux de Paris (AP-HP), Service de Pneumologie, Centre de Référence de l'Hypertension Pulmonaire Sévère, the LabEx LERMIT (grant no ANR-10-LABX-0033), the French PAH patient association (HTAP France) and the french Fonds de Dotation "Recherche en Santé Respiratoire" (FRSR) - Fondation du Souffle (FdS).

302

\section{Conflicts of interest:}

M.R.A.D., R.T., A.C., L.T., G.H., P.G., A.H. and C.G. have no conflict of interest to disclose. In the past 3 years, M.C.C reports nonfinancial support from Actelion, Bayer, Boehringer Ingelheim, and Novartis outside of the submitted work. M.H. and L.S. report grants, personal fees, and nonfinancial support from Actelion, Bayer, GlaxoSmithKline, and MSD, outside of the submitted work. M.H. is a member of the Scientific Advisory Board of Morphogen-IX.

310 Authors' contributions:

311 Conception and design: MCC, LT, and CG; Analysis and interpretation: all; Drafting manuscript: MCC, $\mathrm{LT}$, and CG. 
References:

314

1. Simonneau G, Galie N, Rubin LJ, Langleben D, Seeger W, Domenighetti G, Gibbs S, Lebrec D, Speich R, Beghetti M, Rich S, Fishman A. Clinical classification of pulmonary hypertension. J Am Coll Cardiol 2004;43:5S-12S.

2. McMurray JJ, Packer M, Desai AS, Gong J, Lefkowitz MP, Rizkala AR, Rouleau JL, Shi VC, Solomon SD, Swedberg K, Zile MR, Investigators P-H, Committees. Angiotensin-neprilysin inhibition versus enalapril in heart failure. N Engl J Med 2014;371:993-1004.

3. Casserly B, Klinger JR. Brain natriuretic peptide in pulmonary arterial hypertension: biomarker and potential therapeutic agent. Drug Des Devel Ther 2009;3:269-287.

4. Guignabert C, de Man F, Lombes M. ACE2 as therapy for pulmonary arterial hypertension: the good outweighs the bad. Eur Respir J 2018;51.

5. Andersen S, Axelsen JB, Ringgaard S, Nyengaard JR, Hyldebrandt JA, Bogaard HJ, de Man FS, Nielsen-Kudsk JE, Andersen A. Effects of combined angiotensin II receptor antagonism and neprilysin inhibition in experimental pulmonary hypertension and right ventricular failure. Int $J$ Cardiol 2019;293:203-210.

6. Clements RT, Vang A, Fernandez-Nicolas A, Kue NR, Mancini TJ, Morrison AR, Mallem K, McCullough DJ, Choudhary G. Treatment of Pulmonary Hypertension With Angiotensin II Receptor Blocker and Neprilysin Inhibitor Sacubitril/Valsartan. Circ Heart Fail 2019;12:e005819.

7. Abdelsaid M, Kaczmarek J, Coucha M, Ergul A. Dual endothelin receptor antagonism with bosentan reverses established vascular remodeling and dysfunctional angiogenesis in diabetic rats: relevance to glycemic control. Life Sci 2014;118:268-273.

8. Bordenave J, Thuillet R, Tu L, Phan C, Cumont A, Marsol C, Huertas A, Savale L, Hibert M, Galzi JL, Bonnet D, Humbert M, Frossard N, Guignabert C. Neutralization of CXCL12 attenuates established pulmonary hypertension in rats. Cardiovasc Res 2019.

9. Tu L, Desroches-Castan A, Mallet C, Guyon L, Cumont A, Phan C, Robert F, Thuillet R, Bordenave J, Sekine A, Huertas A, Ritvos O, Savale L, Feige JJ, Humbert M, Bailly S, Guignabert C. Selective BMP-9 Inhibition Partially Protects Against Experimental Pulmonary Hypertension. Circ Res 2019;124:846-855.

10. Poble PB, Phan C, Quatremare T, Bordenave J, Thuillet R, Cumont A, Huertas A, Tu L, Dorfmuller $P$, Humbert M, Ghigna MR, Savale L, Guignabert $C$. Therapeutic effect of pirfenidone in the sugen/hypoxia rat model of severe pulmonary hypertension. FASEB J 2019;33:3670-3679.

11. Tamura Y, Phan C, Tu L, Le Hiress M, Thuillet R, Jutant EM, Fadel E, Savale L, Huertas A, Humbert M, Guignabert C. Ectopic upregulation of membrane-bound IL6R drives vascular remodeling in pulmonary arterial hypertension. J Clin Invest 2018;128:1956-1970. 
12. Guignabert C, Phan C, Seferian A, Huertas A, Tu L, Thuillet R, Sattler C, Le Hiress M, Tamura Y, Jutant EM, Chaumais MC, Bouchet S, Maneglier B, Molimard M, Rousselot $P$, Sitbon $O$, Simonneau G, Montani D, Humbert M. Dasatinib induces lung vascular toxicity and predisposes to pulmonary hypertension. J Clin Invest 2016;126:3207-3218.

13. Tu L, Desroches-Castan A, Mallet C, Guyon L, Cumont A, Phan C, Robert F, Thuillet R, Bordenave J, Sekine A, Huertas A, Ritvos O, Savale L, Feige JJ, Humbert M, Bailly S, Guignabert C. Selective BMP-9 Inhibition Partially Protects Against Experimental Pulmonary Hypertension. Circ Res 2019.

14. Tamura Y, Phan C, Tu L, Le Hiress M, Thuillet R, Jutant E-M, Fadel E, Savale L, Huertas A, Humbert M, Guignabert C. Ectopic upregulation of the Membrane-bound IL6R Drives the Vascular Remodeling in Pulmonary Arterial Hypertension. J Clin Invest 2018.

15. Aiello RJ, Bourassa PA, Zhang Q, Dubins J, Goldberg DR, De Lombaert S, Humbert M, Guignabert C, Cavasin MA, McKinsey TA, Paralkar V. Tryptophan hydroxylase 1 Inhibition Impacts Pulmonary Vascular Remodeling in Two Rat Models of Pulmonary Hypertension. J Pharmacol Exp Ther 2017;360:267-279.

16. Tu L, De Man FS, Girerd B, Huertas A, Chaumais MC, Lecerf F, Francois C, Perros F, Dorfmuller P, Fadel E, Montani D, Eddahibi S, Humbert M, Guignabert C. A critical role for p130Cas in the progression of pulmonary hypertension in humans and rodents. Am J Respir Crit Care Med 2012;186:666-676.

17. Kunichika N, Landsberg JW, Yu Y, Kunichika H, Thistlethwaite PA, Rubin LJ, Yuan JX. Bosentan inhibits transient receptor potential channel expression in pulmonary vascular myocytes. Am J Respir Crit Care Med 2004;170:1101-1107.

18. Wang $C$, Wang J, Zhao L, Wang Y, Liu J, Shi L, Xu M, Wang C. Sildenafil inhibits human pulmonary artery smooth muscle cell proliferation by decreasing capacitative Ca2+ entry. J Pharmacol Sci 2008;108:71-78.

19. Bonniaud P, Fabre A, Frossard N, Guignabert C, Inman M, Kuebler WM, Maes T, Shi W, Stampfli M, Uhlig S, White E, Witzenrath M, Bellaye PS, Crestani B, Eickelberg O, Fehrenbach H, Guenther A, Jenkins G, Joos G, Magnan A, Maitre B, Maus UA, Reinhold P, Vernooy JHJ, Richeldi L, Kolb M. Optimising experimental research in respiratory diseases: an ERS statement. Eur Respir $J$ 2018;51.

20. Koress C, Swan K, Kadowitz P. Soluble Guanylate Cyclase Stimulators and Activators: Novel Therapies for Pulmonary Vascular Disease or a Different Method of Increasing cGMP? Curr Hypertens Rep 2016;18:42.

21. Humbert M, Guignabert C, Bonnet $S$, Dorfmuller P, Klinger JR, Nicolls MR, Olschewski AJ, Pullamsetti SS, Schermuly RT, Stenmark KR, Rabinovitch M. Pathology and pathobiology of pulmonary hypertension: state of the art and research perspectives. Eur Respir J 2019;53. 
22. Chaumais MC, Guignabert C, Savale L, Jais X, Boucly A, Montani D, Simonneau G, Humbert M, Sitbon O. Clinical pharmacology of endothelin receptor antagonists used in the treatment of pulmonary arterial hypertension. Am J Cardiovasc Drugs 2015;15:13-26.

23. Humbert M, Sitbon O, Simonneau G. Treatment of pulmonary arterial hypertension. N Engl J Med 2004;351:1425-1436.

24. Galie N, Humbert M, Vachiery JL, Gibbs S, Lang I, Torbicki A, Simonneau G, Peacock A, Vonk Noordegraaf A, Beghetti M, Ghofrani A, Gomez Sanchez MA, Hansmann G, Klepetko W, Lancellotti P, Matucci M, McDonagh T, Pierard LA, Trindade PT, Zompatori M, Hoeper M. 2015 ESC/ERS Guidelines for the diagnosis and treatment of pulmonary hypertension: The Joint Task Force for the Diagnosis and Treatment of Pulmonary Hypertension of the European Society of Cardiology (ESC) and the European Respiratory Society (ERS): Endorsed by: Association for European Paediatric and Congenital Cardiology (AEPC), International Society for Heart and Lung Transplantation (ISHLT). Eur Respir J 2015;46:903-975.

25. Nielsen PM, Grimm D, Wehland M, Simonsen U, Kruger M. The Combination of Valsartan and Sacubitril in the Treatment of Hypertension and Heart Failure - an Update. Basic Clin Pharmacol Toxicol 2018;122:9-18.

26. Mouchaers KT, Schalij I, de Boer MA, Postmus PE, van Hinsbergh VW, van Nieuw Amerongen GP, Vonk Noordegraaf A, van der Laarse WJ. Fasudil reduces monocrotaline-induced pulmonary arterial hypertension: comparison with bosentan and sildenafil. Eur Respir J 2010;36:800-807.

27. Mouchaers KT, Schalij I, Versteilen AM, Hadi AM, van Nieuw Amerongen GP, van Hinsbergh VW, Postmus PE, van der Laarse WJ, Vonk-Noordegraaf A. Endothelin receptor blockade combined with phosphodiesterase- 5 inhibition increases right ventricular mitochondrial capacity in pulmonary arterial hypertension. Am J Physiol Heart Circ Physiol 2009;297:H200-207.

28. Dempsey EC, Wick MJ, Karoor V, Barr EJ, Tallman DW, Wehling CA, Walchak SJ, Laudi S, Le M, Oka M, Majka S, Cool CD, Fagan KA, Klemm DJ, Hersh LB, Gerard NP, Gerard C, Miller YE. Neprilysin null mice develop exaggerated pulmonary vascular remodeling in response to chronic hypoxia. Am J Pathol 2009;174:782-796.

29. Liczek M, Panek I, Damianski P, Jeczen O, Jazwiec J, Kuna P, Panek M. Neprilysin inhibitors as a new approach in the treatment of right heart failure in the course of chronic obstructive pulmonary disease. Adv Respir Med 2018.

30. Klinger JR, Petit RD, Warburton RR, Wrenn DS, Arnal F, Hill NS. Neutral endopeptidase inhibition attenuates development of hypoxic pulmonary hypertension in rats. J Appl Physiol (1985) 1993;75:1615-1623. 
31. Winter RJ, Zhao L, Krausz T, Hughes JM. Neutral endopeptidase 24.11 inhibition reduces pulmonary vascular remodeling in rats exposed to chronic hypoxia. Am Rev Respir Dis 1991;144:1342-1346.

32. Zhao L, Hughes JM, Winter RJ. Reversal of pulmonary vascular remodelling following hypoxic exposure: no effect of infusion of atrial natriuretic factor and neutral endopeptidase inhibitor. Cardiovasc Res 1994;28:519-523.

33. Thompson JS, Sheedy W, Morice AH. Neutral endopeptidase (NEP) inhibition in rats with established pulmonary hypertension secondary to chronic hypoxia. $\mathrm{Br} J$ Pharmacol 1994;113:1121-1126.

34. Krawutschke C, Koesling D, Russwurm M. Cyclic GMP in Vascular Relaxation: Export Is of Similar Importance as Degradation. Arterioscler Thromb Vasc Biol 2015;35:2011-2019.

35. Lehners M, Dobrowinski H, Feil S, Feil R. cGMP Signaling and Vascular Smooth Muscle Cell Plasticity. J Cardiovasc Dev Dis 2018;5.

36. Hobbs AJ, Moyes AJ, Baliga RS, Ghedia D, Ochiel R, Sylvestre Y, Dore CJ, Chowdhury K, Maclagan K, Quartly HL, Sofat R, Smit A, Schreiber BE, Coghlan GJ, MacAllister RJ. Neprilysin inhibition for pulmonary arterial hypertension: a randomized, double-blind, placebo-controlled, proof-of-concept trial. Br J Pharmacol 2019;176:1251-1267.

37. De Simone V, Guarise P, Zanotto G, Morando G. Reduction in pulmonary artery pressures with use of sacubitril/valsartan. J Cardiol Cases 2019;20:187-190.

38. Zern EK, Cheng S, Wolfson AM, Hamilton MA, Zile MR, Solomon SD, Kittleson MM. Angiotensin Receptor-Neprilysin Inhibitor Therapy Reverses Pulmonary Hypertension in End-Stage Heart Failure Patients Awaiting Transplantation. Circ Heart Fail 2020;13:e006696. 
438 Figure Legend:

439 Figure 1: Study design used to test the efficacy of LCZ 696 alone or in combination with bosentan $(100 \mathrm{mg} / \mathrm{kg} /$ day) $(A)$ in the monocrotaline (MCT) (B) and in Sugen Hypoxia (SuHx) rat 441 models.

Figure 2: Chronic treatments with LCZ 696 and bosentan partially attenuate PH in MCT-injected rats. (A) TAPSE, AT/ET ratio, $R V /(R V / L V)$ distance ratio ( $n=6-12$, biological replicates). (B) mPAP, CO, TPVR, mBP ( $n=5-10$, biological replicates). Values are means $\pm S D$. Comparisons were made using the one-way ANOVA with Bonferroni's post hoc tests. ${ }^{*} p<0.05$, ${ }^{* *} p<0.01,{ }^{* * *} p<0.001,{ }^{* * * *} p<0.0001$ versus control rats; $\# p<0.05, \# \# p<0.01, \# \#$ $\delta p<0.05, \delta \delta p<0.01, \delta \delta \delta p<0.001, \delta \delta \delta \delta p<0.001$ versus MCT rats treated with bosentan alone.

Figure 3: Chronic treatments with LCZ 696 and bosentan attenuate pulmonary vascular remodeling in MCT-injected rats. (A) Representative images of H\&E and $\alpha$-smooth muscle actin ( $\alpha$ SMA) immunostaining, and quantification of the percentage of wall thickness and of muscularized distal pulmonary arteries ( $n=6-11$, biological replicates). (B) Representative images and quantifications of CD68 and PCNA positive cells per pulmonary vessels ( $n=4-6$, biological replicates). Values are means $\pm S D$. Comparisons were made using the one-way ANOVA with Bonferroni's post hoc tests. Scale bar $=50 \mu \mathrm{m}$ in all sections. ${ }^{* *} p<0.01,{ }^{* * *} p<0.001,{ }^{* * * *} p<0.0001$ versus control rats; $\# p<0.05, \#$ \# $<0.01$, $\# \# \# p<0.001$ versus MCT rats treated with vehicle; $\delta \delta p<0.01, \delta \delta \delta p<0.001$ versus MCT rats treated with bosentan alone.

Figure 4: Chronic treatments with LCZ 696 and bosentan attenuate remodeling of the right ventricular wall in MCT-injected rats. Upper left panel: Values of Fulton index/body weight $(n=6-10$, biological replicates). Upper right and bottom panels: Representative images and quantifications of picrosirius staining of $R V$ myocardium tissues ( $n=6-10$, biological replicates). Values are means $\pm S D$. Comparisons were made using the one-way ANOVA with Bonferroni's post hoc tests. Scale bar $=50$ $\mu \mathrm{m}$ in all sections. ${ }^{*} p<0.05,{ }^{* * * *} p<0.0001$ versus control rats; $\# p<0.05, \# \# p<0.001, \# \# \# p<0.001$ versus vehicle-treated MCT rats; $\delta p<0.05, \delta \delta p<0.01$ versus $\mathrm{MCT}$ rats treated with bosentan alone. 

reverse $\mathrm{PH}$ in SuHx rats. (A) TAPSE, AT/ET ratio, $R V /(R V / L V)$ distance ratio ( $n=6-12$, biological replicates). (B) mPAP, CO, TPVR, mBP ( $n=4-7$, biological replicates). Values are means $\pm S D$. Comparisons were made using the one-way ANOVA with Bonferroni's post hoc tests. ${ }^{*} p<0.05$, ${ }^{* *} p<0.01,{ }^{* * *} p<0.001,{ }^{* * * *} p<0.0001$ versus control rats; \#\#p<0.01, \#\#p<0.001 versus SuHx rats treated with vehicle. $A U=$ arbitrary unit.

Figure 6: Chronic treatments with LCZ $696(30 \mathrm{mg} / \mathrm{kg} / \mathrm{d})$ and Bosentan $(100 \mathrm{mg} / \mathrm{kg})$ attenuate remodeling of the right ventricular wall in the SuHx rats. (A) Representative images of H\&E and asmooth muscle actin ( $\alpha-S M A)$ immunostaining, and quantification of the percentage of wall thickness and of muscularized distal pulmonary arteries in lungs of control and MCT-injected rats treated with LCZ 696 alone or in combination with bosentan at the indicated doses ( $n=3-7$, biological replicates). (B) Representative images and quantifications of CD68 and PCNA positive cells per pulmonary vessels ( $n=4-5$, biological replicates). (C) Values of Fulton index/body weight. Representative images and quantifications of picrosirius staining of RV myocardium tissues ( $n=4-7$, biological replicates). Values are means $\pm S D$. Comparisons were made using the one-way ANOVA with Bonferroni's post hoc tests. Scale bar $=50 \mu \mathrm{m}$ in all sections. ${ }^{*} p<0.05,{ }^{* * *} p<0.001,{ }^{* * * *} p<0.0001$ versus control rats; $\# p<0.05$, $\# \#$ p $<0.001, \# \# \# p<0.001$ versus SuHx rats treated with vehicle. $\mathrm{ns}=$ non significant.

Figure 7: Effects of LCZ 696 alone or in presence of bosentan on circulating levels of ANP and CGMP in MCT- and SuHx-rats and on the pro-proliferative phenotype of cultured PA-SMCs derived from idiopathic PAH patients. Quantification of plasma levels of cGMP (A) and (B) ANP ( $n=7-10$, biological replicates). (C) 5-bromo-2-deoxyuridine (BrdU) incorporation in PA-SMCs derived from 2 patients with idiopathic PAH under basal condition ( $0 \%$ fetal calf serum or FCS) or in response to LCZ 69 with or without bosentan in presence of $5 \%$ FCS ( $n=8$, technical replicates). Values are means $\pm S D$. Comparisons were made using the one-way ANOVA with Bonferroni's post hoc tests. ${ }^{*} p<0.05,{ }^{* *} p<0.01,{ }^{* * *} p<0.001,{ }^{* * * *} p<0.0001$ versus control rats or Vehicle. \#\#p<0.01, \#\#p<0.01, \#\#\#p<0.0001 versus MCT or SuHx rats treated with vehicle or Vehicle in presence of $5 \%$ FCS. 
A
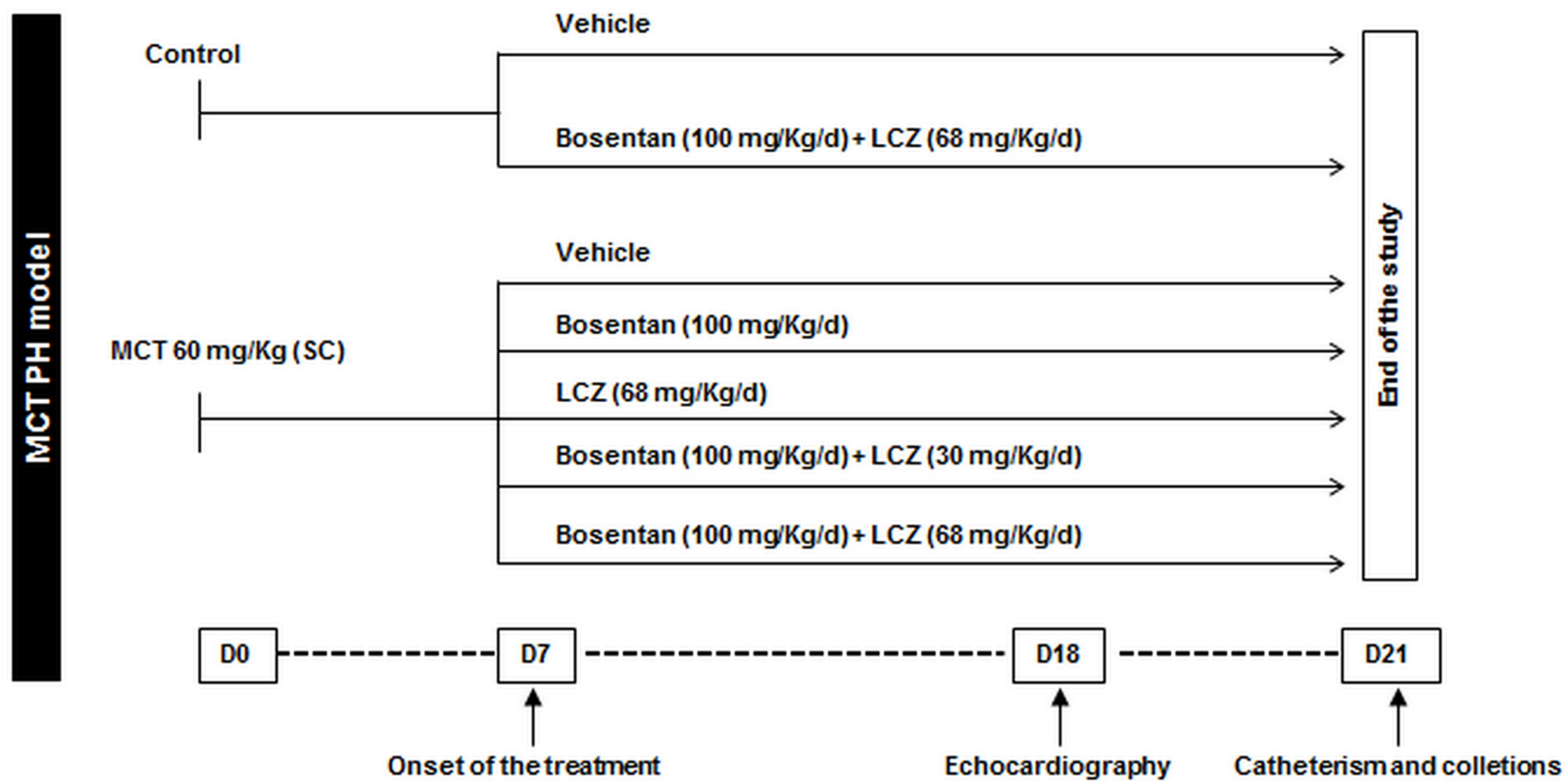

Control
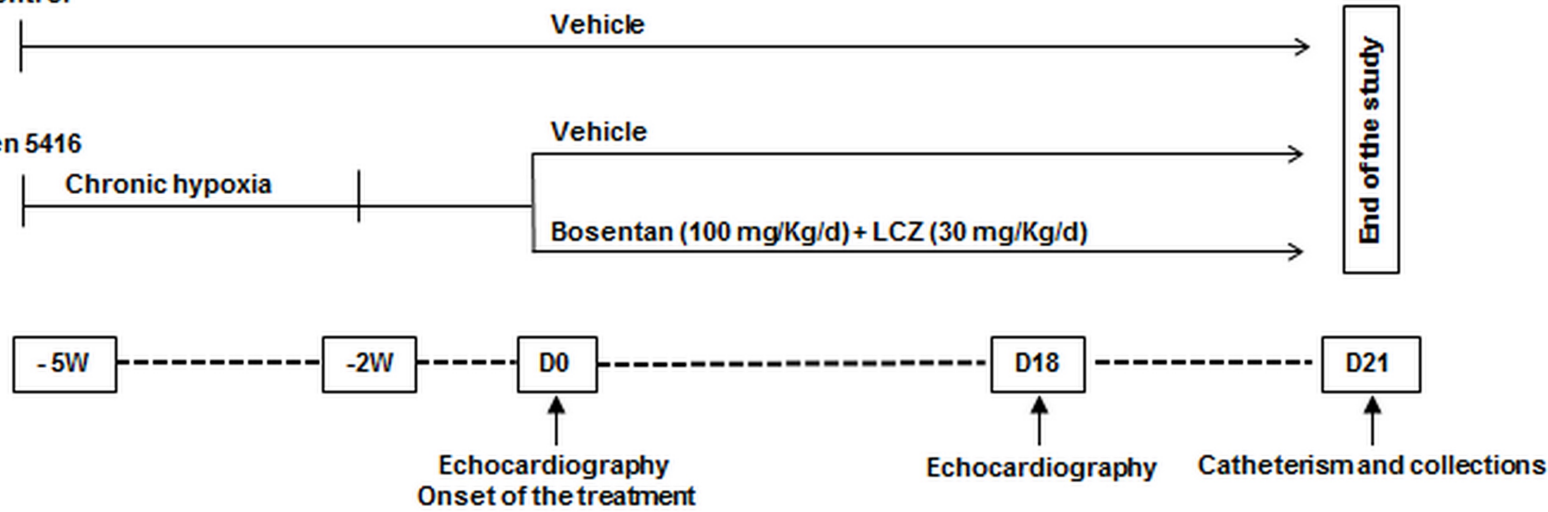


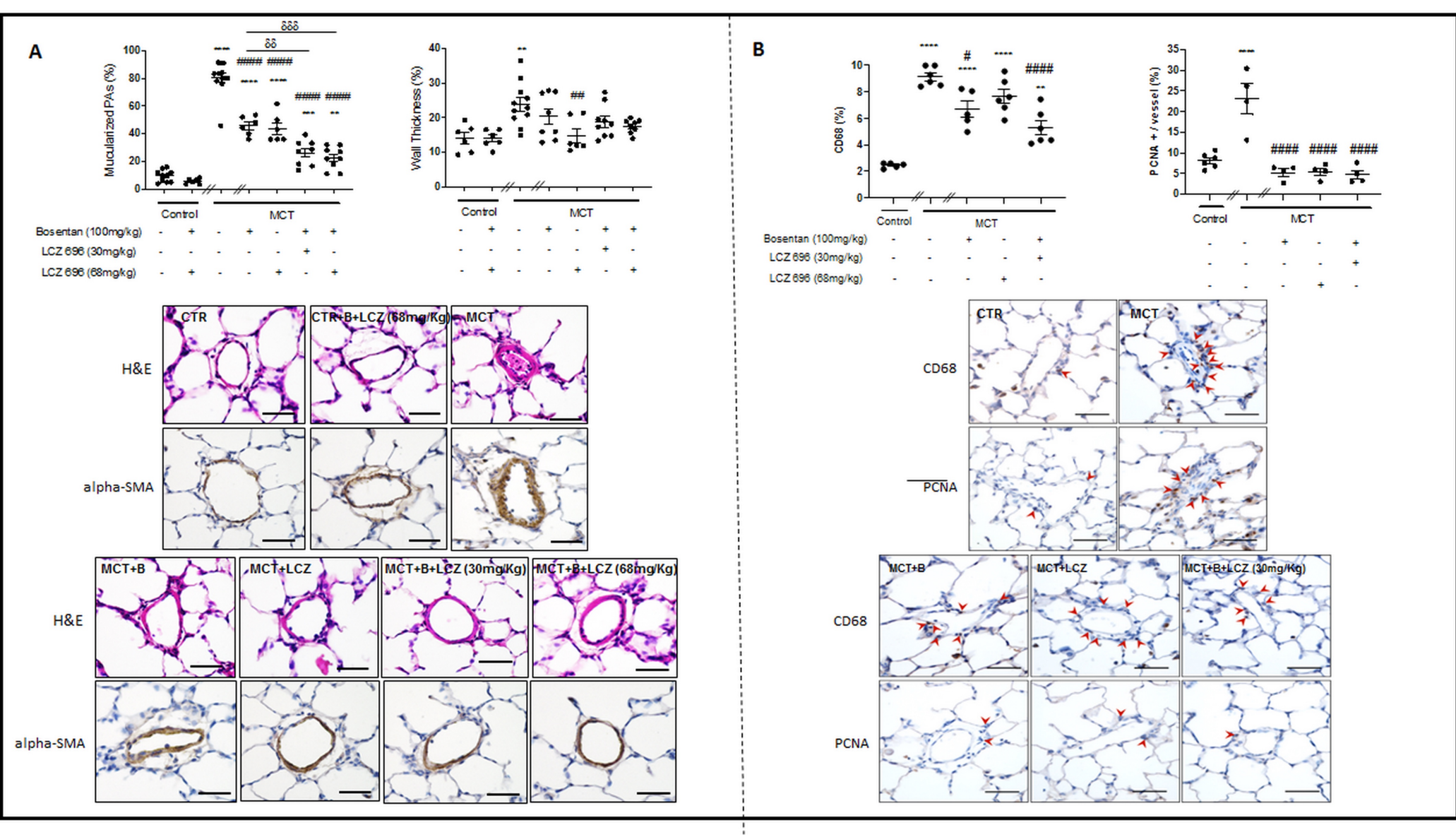



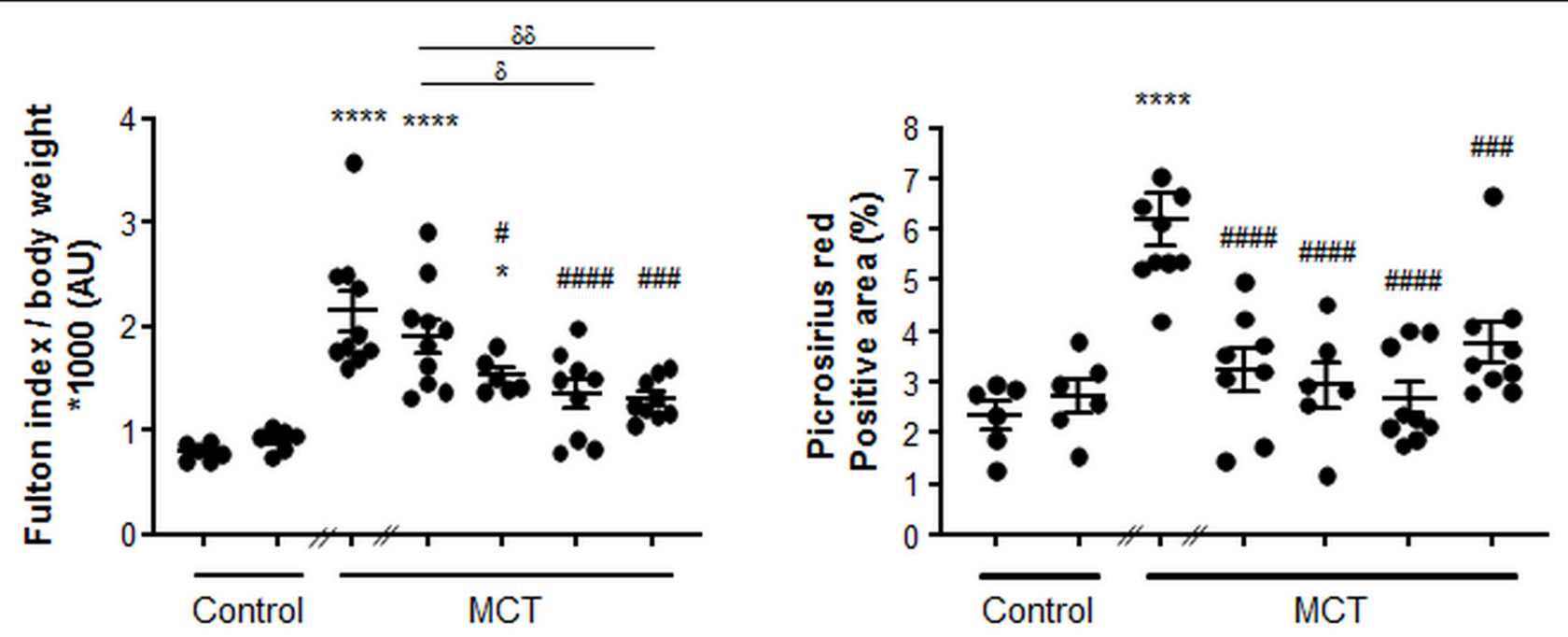

Bosentan (100mg/kg) -

LCZ 696 (30mg/kg) -

LCZ 696 (68mg/kg)

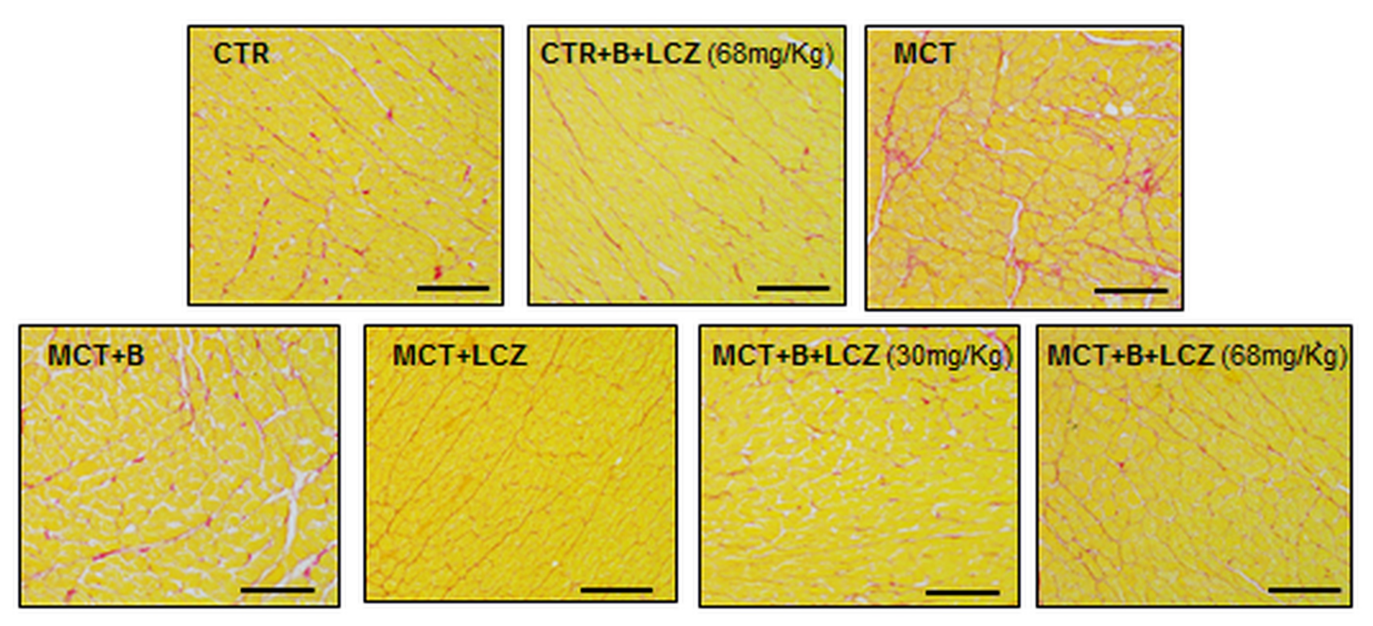




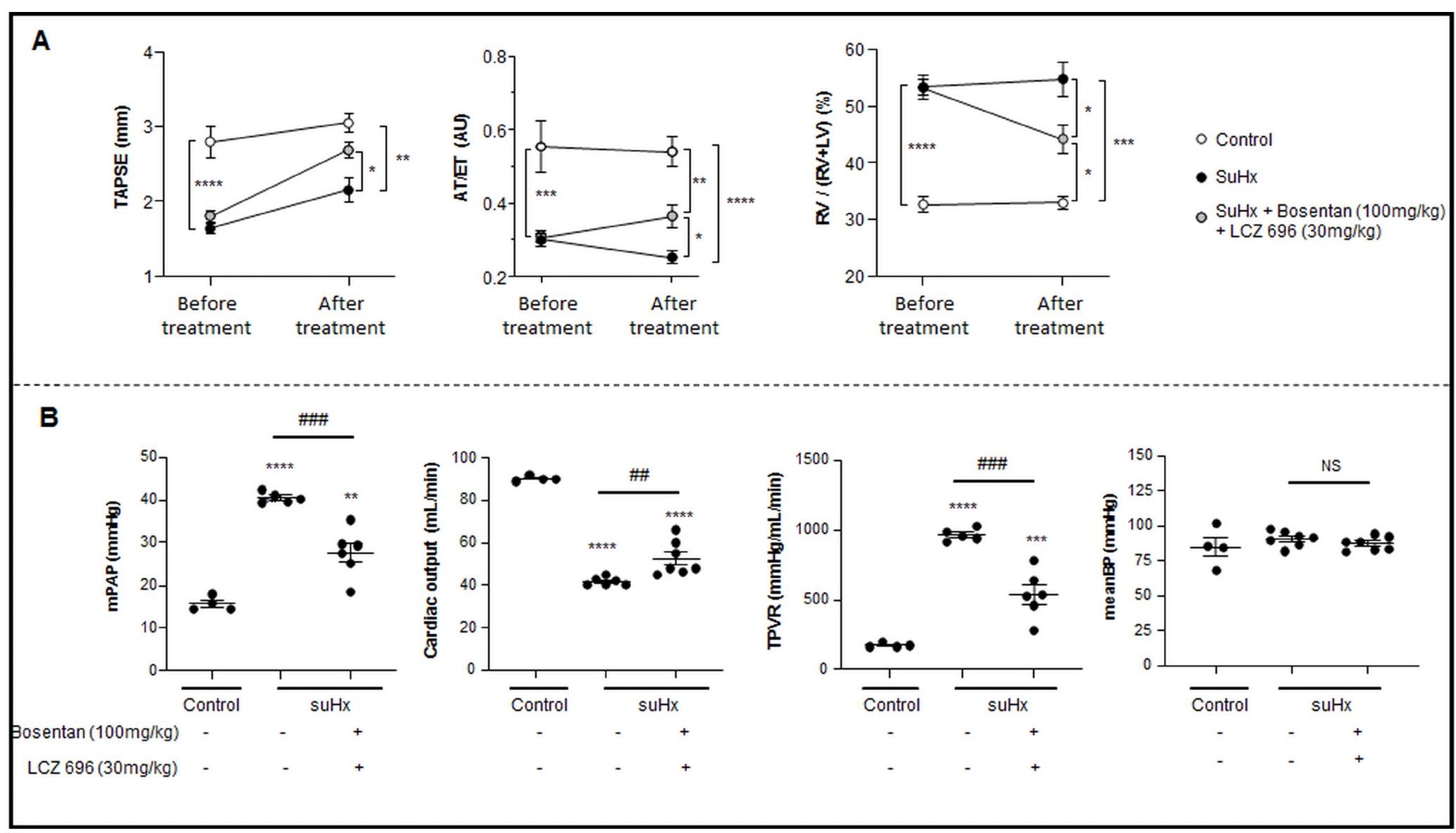




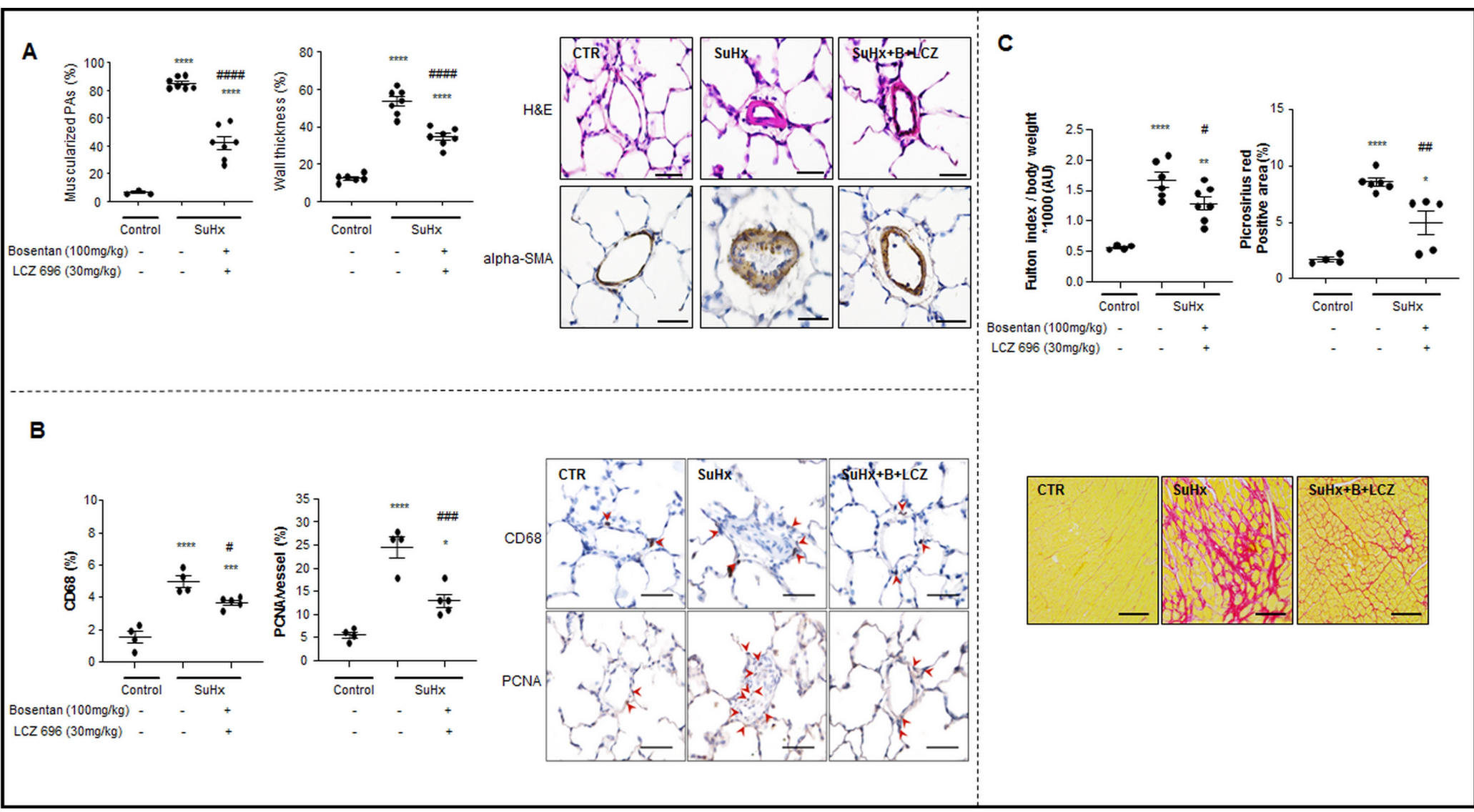




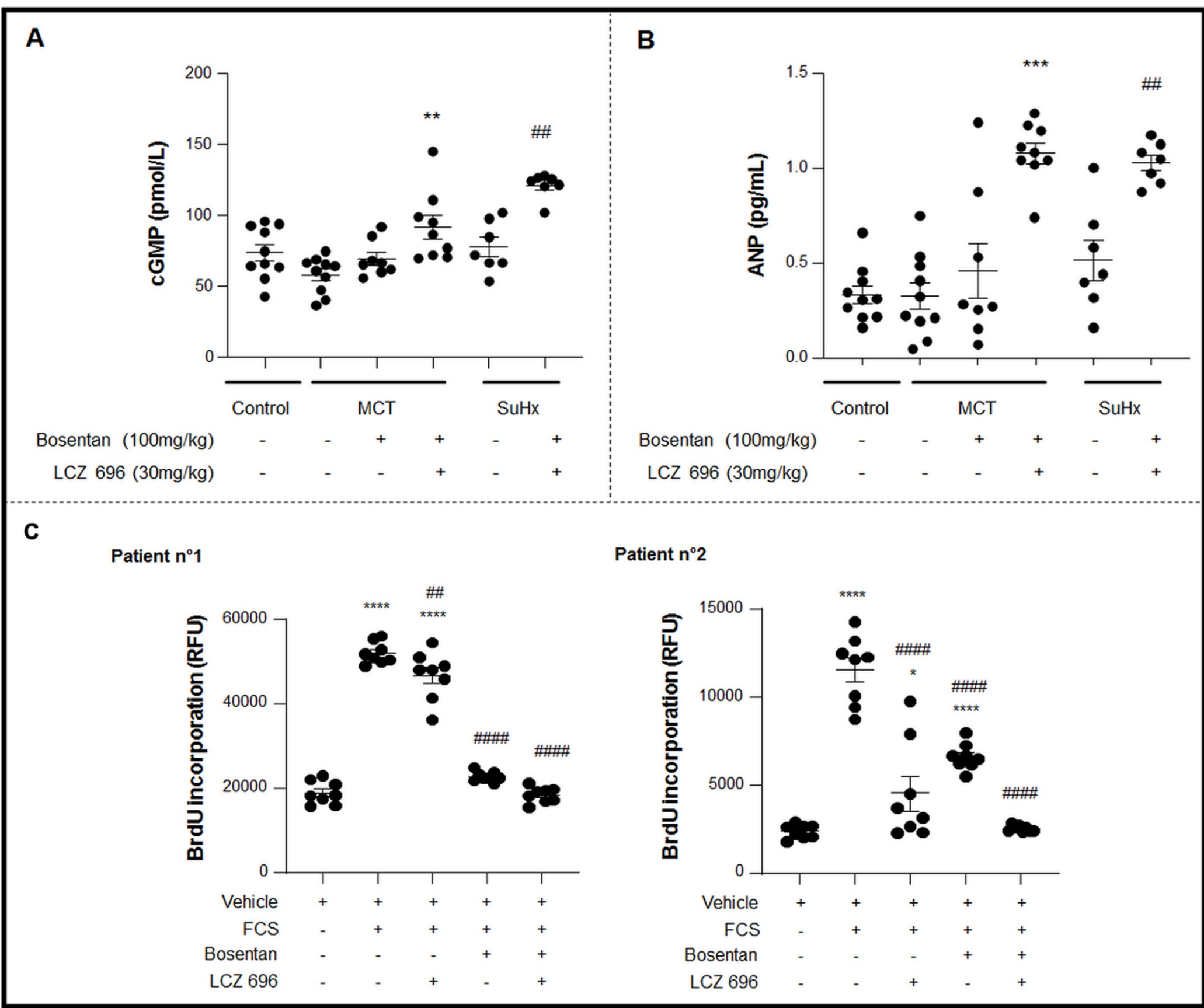

